\title{
A ciência e os riscos ambientais vinculados ao sistema agroalimentar moderno*
}

\author{
Science and the environmental risks related \\ to the modern agri-food system
}

Elaine de Azevedo**

Palavras- Resumo: O objetivo deste estudo conceitual é compilar algumas chaves: discussões que envolvem a ciência e os riscos vinculados ao sistema Ciência; Riscos ambientais;

Sistema agroalimentar;

Sociologia ambiental. agroalimentar que emergiram já na década de 1990 e continuam a promover férteis discussões sociológicas uma vez que novos riscos continuam a aparecer. Para cumprir tal objetivo, foram mobilizados autores da Sociologia Ambiental e da abordagem construtivista dos riscos, além de referências de diversos riscos alimentares. A legitimação desses riscos, resultado de um complexo e heterogêneo processo de definição, negociação e legitimação em arenas públicas e privadas, envolve diferentes atores. Entretanto, neste artigo, a ciência será explorada como ator central, devido a sua grande influência sobre as decisões e sobre as políticas públicas de riscos ambientais ligadas ao sistema agroalimentar moderno e ao seu papel frente à legitimação dos mesmos. O estudo mostra que a avaliação dos riscos alimentares é complexa e multifacetada, e sua interpretação e construção são contestáveis e frequentemente partidárias, uma vez que os vários grupos envolvidos usam a linguagem da ciência para defender seus interesses. Para minimizar tais problemas, sugerem-se pesquisas de caráter inter e transdisciplinar para ampliar a visão reducionista que impera nos estudos de riscos alimentares, bem como novas relações entre as racionalidades científica e social, e a adoção de uma abordagem situacional para essas preocupações. Destacam-se a necessidade de estudos locais que se debrucem sobre a arena sociológica de riscos alimentares e o papel dos seus diferentes atores que permitam embasar ações de controle de riscos alimentares, aperfeiçoar mercados consumidores e estimular sistemas agroalimentares preocupados com a segurança alimentar e nutricional.

\footnotetext{
* Artigo recebido em 14/03/2013 e aceito para publicação em 10/06/2013.

** Doutora em Sociologia Política pela UFSC e Professora Adjunta da Universidade Federal do Espírito Santo, Centro de Ciências Humanas e Naturais, Departamento de Ciências Sociais. E-mail: elainepeled@gmail.com.
} 
Keywords: Abstract: The objective of this conceptual study is to compile some Science; discussions which involve science and the risks linked to the agriEnvironmental food system which emerged in the 1990s and continue to promote risks; Agri-food fertile sociological debates, as new risks continue to appear. To system; attain this objective, we mobilized authors from the area of Environmental environmental sociology and the constructive approach to risk, as sociology. well as references to various food risks. Legitimization of these risks, which is the result of a complex and heterogeneous process of definition, negotiation, and legitimization in public and private arenas, involves different actors. Nevertheless, in this study science will be explored as the central actor, due to its large influence on decisions and on public policy for risks related to the modern agrifood supply, and also due to its role in legitimizing these risks. The study shows that evaluation of food risks is complex and multifaceted, and its interpretation and construction are contestable and frequently partisan, as the various groups involved use the language of science to defend their own interests. To minimize such problems, we suggest interdisciplinary and trans-disciplinary studies to expand the reductionist vision which prevails in studies of food risks, as well as new relationships between the scientific and social rationales and the adoption of a situational approach for these concerns. We also stress the need for local studies that address the sociological arena of food risks and the role of the different actors therein, which underlie activities to control food risks, perfect consumer markets, and stimulate agri-food systems which are concerned with food and nutritional security.

\section{Introdução}

$\mathrm{G}$ rande parte dos riscos ambientais são ameaças genuínas e sua análise não deve se limitar apenas a percepções e formulações sociais. Essa é a percepção de Hanningan (2006), que também sustenta que uma abordagem construtivista dos riscos ambientais deve reconhecer que eles são resultados de um processo sociodinâmico de definição, negociação e legitimação em arenas sociais de risco públicas e privadas, envolvendo grupos de ativistas, cientistas e especialistas, empresas e indústrias, atores governamentais, imprensa e mídia, bem como o público em geral.

Duas tarefas centrais nessa temática são: entender por que certas condições são percebidas como "de risco" e como tornar tais riscos legítimos e reconhecidos em termos de atenção política aos mesmos.

Uma construção satisfatória para delinear um determinado risco ambiental, segundo Hannigan (2006), envolve diferentes fatores e um conjunto complexo de elos sociais e organizacionais: os geradores de riscos 
(protagonistas primeiros dos riscos); os portadores de riscos (vítimas que suportam os custos diretos dos riscos); os defensores dos portadores de riscos (que lutam pelo direito das vítimas); a autoridade científica, a validação da reivindicação e os investigadores de risco (que agem em nome da ciência); os árbitros do risco (mediadores, tribunais, agências reguladoras que agem de fora do palco determinando a extensão, a responsabilidade e a forma de penalidade); a popularidade (que constrói uma ponte entre os ambientalistas e os cientistas); os informadores do risco (os meios de comunicação e a mídia); a dramatização do problema em termos simbólicos e visuais; e a emergência de uma instituição patrocinadora que possa conferir legitimidade e continuidade ao problema.

Cada um desses fatores merece ser analisado com profundidade, mas este artigo vai se dedicar à autoridade científica e ao papel da ciência frente à legitimação dos riscos por considerar sua grande influência sobre as decisões e sobre as políticas públicas de risco. Outro aspecto que justifica essa escolha é que tal fator se envolve com todos os demais e permite a construção de uma instigante teia de análise de riscos.

O tema não é novo e vem sendo abordado por diferentes autores desde a década de 1990. O que este artigo propõe é compilar alguns aspectos centrais da análise construtivista dos riscos ambientais envolvendo a autoridade científica, com foco para os riscos alimentares vinculados ao Sistema Agroalimentar Moderno.

Para explorar a temática proposta, foi utilizada uma pesquisa conceitual mobilizando autores da área da Sociologia Ambiental e da abordagem construtivista dos riscos, além de referências de diversos riscos alimentares que vêm surgindo desde a década de 1990. Num primeiro momento, serão abordadas as transformações da ciência e a prática da reflexividade frente aos riscos de caráter ambiental. O artigo vai abordar em um segundo momento uma discussão que envolve elementos da Sociologia do Conhecimento Científico frente a tais riscos, a partir da contribuição de autores que discutem riscos ambientais e de estudos que se dedicam aos riscos ambientais relacionados ao sistema agroalimentar moderno, também chamados aqui de riscos alimentares.

A ansiedade relacionada às incertezas em torno do tripé alimentaçãosaúde-doença tem se expressado de forma cada vez mais intensa. A sociedade já convive há tempos com parâmetros de riscos relacionados principalmente à escassez de alimentos e à segurança alimentar, e hoje conhece novos riscos e ameaças, decorrentes do uso de novas tecnologias aplicadas à produção e transformação dos alimentos. 
A mídia e as instituições de vigilância sanitária e proteção ao consumidor estão atentas a tais riscos que englobam doenças relacionadas ao manejo (encefalopatia bovina espongiforme, febre aftosa, gripes aviária e suína), ao uso de tecnologias (irradiação, transgenia, nanotecnologia) e às contaminações durante o processo produtivo ou industrial. Neste último âmbito ressaltam-se as contaminações químicas (agrotóxicos, fertilizantes, aditivos, drogas veterinárias, metais pesados, produtos de higienização de embalagens) e as contaminações biológicas.

Beck (1992) afirma que na sociedade de classes a força motriz para delinear os riscos podia ser resumida na frase "eu tenho fome" (p. 49). Por outro lado, na sociedade atual, o sentimento coletivo diante dos riscos é expresso pela afirmação "eu tenho medo" (p. 49), que no campo da alimentação pode ser resumido na pergunta "o que eu devo comer?". Apesar de a tecnologia moderna ter ajudado a minimizar os riscos da fome e a contornar outros, como as contaminações biológicas e as adulterações alimentares, outras ansiedades mais sutis, vinculadas ao consumo de alimentos, antes mascaradas ou de relativa baixa visibilidade, tornaram-se proeminentes e ganharam a atenção do público em geral. Tais riscos se caracterizam na perspectiva de riscos ambientais com consistentes repercussões sociais.

\section{A ciência frente aos riscos ambientais}

A partir do século XVIII, a ciência tornou-se elemento de referência para delinear a mudança no modo de aquisição do conhecimento - que deveria buscar a verdade dos fatos - e para delimitar a transição da tradição para a modernidade.

Ainda hoje a ciência é percebida como o "meio mais bem-sucedido de criação do conhecimento e lida exclusivamente com argumentos baseados em evidências". Essa fala de Michael Clegg, presidente da Rede Interamericana das Academias de Ciência, ${ }^{1}$ endossa a importância de "ouvir a voz da ciência" para resolver problemas mundiais como as mudanças climáticas, doenças emergentes, crescimento populacional e as consequentes dificuldades no abastecimento de alimentos, água e energia. Para Clegg, "para que o desenvolvimento global seja possível, a ciência e os cientistas precisam atingir um grau maior de influência em todo o mundo". O encontro de cientistas preparatório para o Fórum Mundial da Ciência de 2013

\footnotetext{
1 Discurso proferido no I Encontro Preparatório para o Fórum Mundial de Ciência 2013, realizado na sede da FAPESP, São Paulo, entre 29 e 31 de agosto de 2012. Disponível em: [http://agencia.fapesp.br/16118]. Acesso em: [31 ago. 2012].
} 
defendeu a ideia de que a sustentabilidade só se alcança com o uso intensivo do conhecimento científico e tecnológico.

Hannigan (2006) também mostra que muitos autores insistem que as decisões sobre riscos ambientais devem ter base eminentemente científica em detrimento de critérios políticos e sociais. Nesse contexto, a política não pode ser utilizada para parar a ciência, enquanto a ideologia da perícia científica relativa às novas tecnologias ainda considera a intervenção pública como insensata. O próprio Michael Clegg ressalta que as academias de ciência devem ser "instituições livres de interferência política".

Paralela a essa perspectiva que ainda mantém a percepção da ciência como detentora legítima e central do conhecimento, uma abordagem contemporânea a coloca no cerne de debates sociais, na medida em que as incertezas científicas se multiplicam e representam um elemento central na análise sociológica dos riscos socioambientais.

A grande maioria dos problemas ambientais busca um embasamento científico. Mas, paradoxalmente, em casos de riscos ambientais e em situações nas quais a ciência não é capaz de oferecer provas inequívocas de segurança, a própria racionalidade científica é rejeitada em favor de uma alternativa de racionalidade cultural que apela ao conhecimento do povo e das tradições. Nesses casos, a ciência é criticada por intervir na ordem natural (HANNIGAN, 2006).

Beck (1995) é crítico quando se reporta ao papel da ciência frente aos riscos e problemas ambientais. Para o sociólogo, a ciência serve como instituição protetora da contaminação e fica ao lado das instituições e contra a ansiedade dos consumidores. A ciência e a tecnologia não solucionam os problemas, mas se tornam suas causas. Para o sociólogo alemão, muitos dos problemas que a ciência está enfrentando foram criados por ela que, por sua vez, não foi sempre capaz de oferecer soluções. A ciência que surgiu como uma libertação dos fatores condicionantes da natureza é percebida atualmente como criadora de riscos, com limitações cada vez mais visíveis. Assim, ela já não representa somente o esclarecimento, mas também "uma força adversária", nas palavras de Irwin (2001, p. 62).

Os riscos relacionados aos pesticidas ilustram bem essa perspectiva. Essa tecnologia que já se configurou como estratégia central da agricultura moderna para combater pragas e aumentar a produtividade é hoje relacionada à promoção de diversas enfermidades e à contaminação ambiental. Apesar das mantidas controvérsias entre os defensores do seu uso e aqueles que os questionam, a mudança de termo - de defensivo agrícola para agrotóxicos - incorpora e evidencia a preocupação com os riscos e a toxicidade desses agentes. Essa característica fica completamente 
mascarada na denominação anterior de caráter positivo que remete à ideia popular de 'remédio para plantas'.

Para Irwin (2001), a abordagem de desencantamento do mundo em Beck não oferece soluções ou sólidos fundamentos para construir um cenário positivo. Entretanto, essa perspectiva weberiana oferece à Sociologia a possibilidade de adotar uma posição crítica nos assuntos que envolvem o papel da ciência.

Mas existem outras perspectivas mais positivas do que a de Beck que evidenciam possíveis soluções e não descartam o papel de uma ciência renovada diante dos riscos da contemporaneidade. De acordo com Irwin (2001, p. 57), ainda se depende da ciência não como "monopólio da racionalidade", mas como uma proposta plural, reflexiva e atenta a uma redefinição de si mesma.

Esse ponto de vista interessa particularmente a esse estudo uma vez que a modernidade reflexiva amplia o número de questões sobre o papel e a origem da ciência na solução dos riscos e problemas ambientais. Não se objetiva questionar o papel da ciência, mas, reflexivamente, ressaltar sua natureza não homogênea e as influências que ela sofre durante a construção dos riscos. Irwin (2001) ressalta que quando não existe um senso comum para determinar os riscos a avaliação dos mesmos é uma combinação de racionalidade científica, deliberação institucional e esforços de uma nova organização política e ambiental.

A reflexividade é uma consequência do retorno da incerteza e dos riscos e serve de instrumento não somente para questionar o papel da ciência, como também os aspectos rotineiros da vida social, referindo-se "[...] à suscetibilidade da maioria dos aspectos da atividade social, e das relações materiais com a natureza, à revisão intensa à luz do novo conhecimento ou informação" (GIDDENS, 2002, p. 26).

Para Beck (1995, p. 12), a reflexividade significa a possibilidade de uma (auto) destruição criativa da era da sociedade industrial e a "desincorporação, seguida da reincorporação das formas sociais industriais por outra modernidade". Tal modernidade reflexiva é acompanhada de uma dissolução do dinamismo das instituições modernas, nas quais o progresso pode ser transformado em autodestruição.

Hoje é comum desconfiar dos próprios sentidos para fazer julgamentos sobre os riscos associados ao que se deve comer e a opção dos leigos é consultar especialistas. Porém, Bauman (2001) adverte que, na modernidade reflexiva, os sistemas peritos também se tornam vulneráveis diante dos iminentes riscos contabilizados e o indivíduo contemporâneo acaba fazendo escolhas rotineiras que geram ansiedade e insegurança. A 
proliferação de estudos controversos sobre os benefícios e/ou riscos de alimentos colocam o sistema agroalimentar e a ciência da nutrição na pauta das discussões sobre riscos ambientais.

Mas toda ciência, como instrumento de legitimação ou questionamento dos riscos, é hoje, portanto, um dos principais objetos da reflexividade e vem sendo questionada na forma como foi concebida no início da modernidade. A modernidade reflexiva parece estar transformando a ciência em um tipo de categoria ou instituição zumbi, para utilizar o termo de Bauman (2001). O autor explica que essas categorias estariam, superadas em termos do poder designativo que possuíram em épocas relativamente recentes, mas, ao mesmo tempo, também válidas porque ainda servem aos propósitos de trazer alguma significação e inteligibilidade aos referentes que descreviam.

A prática da reflexividade confunde as premissas do pensamento iluminista que acreditava que a razão superaria os dogmas da tradição. Para além dessa afirmação, Giddens (2002) enfatiza que a ciência depende do princípio metodológico da dúvida e deve estar aberta à revisão a partir do desenvolvimento de novas ideias ou descobertas. Essa condição de incerteza coloca numa condição perturbadora não somente os leigos, mas também os peritos - os especialistas e os cientistas.

Nesse contexto, a ciência é revista à luz dos problemas por ela causados e torna-se permeada por controvérsias.

\section{Abordagem construtivista dos riscos ambientais e alimentares}

Os aspectos relacionados neste item estão baseados nas discussões sobre riscos ambientais numa abordagem construtivista já explorada por Guivant (2002) e por autores como Irwin (2001), Wynne (1992), Hinchliffe (2001), além de outros que contribuem de forma indireta. Beck (1995) é central na análise ao definir risco ambiental como risco fabricado a partir da intervenção humana - conhecimento e da tecnologia - com impactos sobre o mundo natural. Guivant (2002) reitera que tais riscos não são apenas efeitos colaterais do progresso, mas são estruturais no que diz respeito a suas fontes e abrangência. São riscos globais incontroláveis, de graves consequências, desconhecidos a longo prazo, que não podem ser avaliados com precisão, que demandam estudos transdisciplinares para sua compreensão e que atingem a todos, indistintamente. Tais elementos de análise podem ser utilizados para delinear grande parte dos riscos alimentares que ameaçam a sociedade contemporânea e podem ser estendidos para diversos tipos de riscos ambientais. 
O primeiro e talvez o mais essencial aspecto a considerar é que os riscos ambientais - e grande parte dos alimentares - não são impostos às sociedades, nem podem ser percebidos como uma força externa que tem impacto sobre a estrutura social, mas são construídos socialmente dentro de uma complexa e heterogênea arena social.

Destacam-se, ainda, a questão que diz respeito à variedade de especialistas envolvidos na discussão desses riscos e a necessidade de conjugar os variados interesses, que precisam chegar a uma linguagem comum. Cada um desses especialistas possui sua própria estrutura intelectual e institucional operando sob princípios e focos de atenção diversos, o que, muitas vezes, dificulta a construção de consensos. No caso dos insumos sintéticos utilizados na agricultura, por exemplo, a análise epidemiológica de um especialista da saúde humana envolvido na discussão que envolve contaminação química é muito diferente da análise de dependência econômica desses insumos por parte da agricultura familiar produzida por um cientista vinculado à Agroecologia e se afasta ainda mais da visão dos agrônomos defensores da alta produtividade da monocultura, apesar de todas as avaliações poderem ser qualificadas como científicas.

Tansey e Worsley (1995) fornecem outros exemplos que ilustram a problemática. Alguns profissionais da área de Microbiologia desconsideram as questões relativas ao impacto nutricional das tecnologias alimentares, enquanto a Engenharia de Alimentos, ao desenvolver tecnologias para agilizar a morte de animais, muitas vezes, deixa de lado as questões relativas à segurança sanitária e ao bem-estar animal. Já os profissionais da Tecnologia de Alimentos priorizam o desenvolvimento de técnicas de preservação dos alimentos que, além de garantir a inocuidade dos mesmos, aumentam seu tempo de prateleira e barateiam seus custos. Porém, tais práticas nem sempre favorecem a qualidade nutricional do produto e a saúde dos consumidores, como é o caso da irradiação.

Outro aspecto, que se mescla com o primeiro, é a localidade institucional do debate dos riscos. A perspectiva construtivista de riscos sugere a necessidade de pontuar a variedade social de grupos envolvidos nas argumentações técnicas sobre um determinado tipo de risco. Exemplificando 0 caso dos riscos de alimentos contaminados por agrotóxicos, ressaltam-se diferentes entidades: os departamentos governamentais, a indústria de insumos agrícolas ou de alimentos, as ONGs ambientalistas, as associações de agricultores ou consumidores, os grupos internacionais de importação de alimentos e a comunidade local vivendo perto dos campos produtivos. Cada um desses grupos vai produzir uma avaliação social e técnica da segurança (ou insegurança) dos alimentos 
contaminados. Nessa abordagem é essencial explorar os diferentes usos da ciência feitos por diferentes grupos envolvidos e também analisar as formas que cada grupo envolvido na discussão elege para gerar conhecimento sobre o tema em questão.

Ainda no contexto de localidade dos riscos, Jasanoff (1986) aponta uma perspectiva transnacional que também afeta a formulação dos riscos ambientais. Tal perspectiva inclui a organização das estruturas políticas e administrativas, as tradições históricas e crenças culturais de diferentes países que influenciam os objetivos e as prioridades na gestão do risco. Um exemplo de divisões políticas transnacionais frente aos riscos pode ser encontrado na análise de riscos dos alimentos transgênicos, cuja abordagem no Canadá, nos EUA, na Argentina e no Brasil é fundamentalmente apoiada pelo princípio da equivalência; já a posição adotada pela Comunidade Europeia se apoia no princípio da precaução.

Maria Fonte, citada por Pessanha e Wilkinson (2005), ao analisar os riscos relacionados aos alimentos transgênicos, sugere que eles são resultados de vários tipos de divisões: divisões políticas transatlânticas, já abordadas acima; uma divisão científica entre visões reducionistas e sistêmicas da ciência; e também uma divisão institucional entre ideias de privatização e democratização da ciência; ou seja, entre aqueles que acreditam no progresso científico causado pela privatização do conhecimento e aqueles que defendem o domínio público da ciência e um sistema de acesso livre e compartilhado de produção de ideias, como base de uma sociedade de conhecimento mais democrática. Jarvie e Agassi (2011, p. 77) ao analisar as divisões e fissuras departamentais das academias em que se produzem ciência compartimentada mostram que elas "são promovidas por disputas sobre o mundo e sobre como as pesquisas devem ser conduzidas". Guivant (2005) demonstra como essas divisões se apresentam, ao analisar o processo decisório de liberação de transgênicos no Brasil.

Uma questão que se inter-relaciona com essa é o contexto social e institucional dentro do qual a ciência moderna é produzida, pois levanta discussões sobre a relação entre os fundos de financiamento e o local do estudo com o tipo de pesquisa conduzida, bem como a discussão que envolve o mercado como regulador das decisões tecnológicas. Cabe aqui citar as chamadas mandated science e regulatory science.

Para Salter (1988), a mandated science ressalta o papel dos cientistas e da ciência na formulação de políticas reguladoras dos riscos a partir de encomendas e pressões feitas por agentes governamentais e reguladores que influenciam na tomada de decisões. Essa forma de ciência apresenta certa autonomia dentro do campo científico, com suas próprias regras e 
características e a participação central dos peritos. Salter identifica ainda diversas escolhas valorativas nas atividades da mandated science, tais como: que estudos recomendar; como interpretar os resultados incertos, ambíguos ou não diretamente operacionalizáveis; quem é responsável pela (in) segurança de determinados produtos.

Irwin et al. (1997) definem regulatory science como formas de ciência desenvolvidas dentro da indústria a partir de suas necessidades e preocupações. Apesar de fazer uma distinção inicial entre a prática de pesquisa industrial e acadêmica, Irwin (2001) ressalta que hoje a prática acadêmica de pesquisa também mudou e em muitas universidades os fundos de pesquisa são mantidos por indústrias.

Fallon e Enig (2000) afirmam que a melhor estratégia de marketing para um produto alimentar é ter um parecer científico sobre saúde. Muitas pesquisas são realizadas com financiamento de instituições públicas, mas indústrias de alimentos, conselhos de produtores e empresas produtoras de sementes proveem informação e fundos de pesquisa para instituições acadêmicas, institutos de pesquisa e associações de profissionais, além de apoiar congressos e periódicos. Nem sempre tal apoio significa exigir estudos manipulados, mas quando uma corporação financia a ciência há mais chances de se enfatizar efeitos favoráveis aos interesses das empresas - e provavelmente os resultados negativos nunca são publicados.

Novos conhecimentos científicos e desenvolvimentos tecnológicos levaram a grandes mudanças no sistema alimentar. Atores dos diferentes setores financiam uma vasta gama de pesquisas recorrendo a uma sofisticada tecnologia. O uso dos resultados é de vital interesse para a indústria e aqueles que podem introduzir inovações ganham os maiores benefícios (TANSEY; WORSLEY, 1995).

Um exemplo de pesquisa com impactos positivos para a indústria é aquela que envolve alimentos funcionais (com parecer de saúde), que aparece vinculada à imagem de uma indústria alimentar comprometida com a qualidade de vida e bem-estar de seus potenciais clientes consumidores (BURCH; LAWRENCE, 2010).

Para Tansey e Worsley (1995), a pergunta central no sistema agroalimentar é: que tipo de pesquisa é feita e a quem ela beneficia? Isso também se relaciona com outras questões como: quem financia a pesquisa, quem tem propriedade sobre os resultados, onde estão as prioridades? Os precursores das novas tecnologias têm algum tipo de responsabilidade sobre seus efeitos? As forças que moldam a agenda da pesquisa e da tecnologia utilizada afetam o que é descoberto, focam a direção da pesquisa e proveem produtos que servem para objetivos específicos. Para a maioria dos 
cientistas é contratada e segue as regras que regem os fundos de pesquisa ou os interesses dos atores que estão contratando. Parece muito difícil, nesse âmbito de pesquisa, que os cientistas persigam seus próprios e puros objetivos científicos. Se as áreas de pesquisa crescentes são aquelas que aumentam a rentabilidade de um produto, outra pergunta que surge é: rentabilidade de quem e como ela é definida? (TANSEY; WORSLEY, 1995),

$\mathrm{O}$ que tais questões traduzem é uma desconfiança acerca do apoio da indústria de alimentos e sua influência nos resultados de pesquisas e das opiniões dos especialistas. Essa é uma dúvida que dificilmente encontrará sua resposta definitiva e o quadro a seguir, retirado do livro da nutricionista Marion Nestle (2002), pode gerar mais inquietações nesse sentido. O quadro mostra citações literais traduzidas de investigações e a origem de seus autores, todos apoiados por empresas alimentares ou por associações e/ou conselhos de produtores de alimentos (os influentes Councils e Boards norte-americanos). Como já mencionado acima, Nestle ressalta que esses dados não sugerem que a pesquisa financiada por tais atores é sempre parcial, mas sinalizam a grande probabilidade de surgirem conclusões favoráveis aos interesses comerciais dos empresários.

Quadro 1: citações de estudos científicos e a origem de seus autores

"Alta quantidade de fibras nos cereais de café da manhã podem ajudar a reduzir riscos de
câncer associados com a baixa ingestão de fibras." (O autor é empregado da Kellogs do
Reino Unido).
"Comer dois ovos por dia durante 12 meses resulta em um mensurado efeito estatístico na
diminuição do colesterol LDL..." (Estudo financiado em parte pelo Eggs Nutrition Center).
O consumo de margarina comparado com o de manteiga diminui os níveis de colesterol LDL
na taxa de $11 \%$ em adultos e $9 \%$ em crianças pesquisados." (Entre os patrocinadores do
estudo estão a United Soy Board Association e a National Association of Margarine
Manufactures). "Estudos científicos indicam que a prevalência de intolerância à lactose - o açúcar do leite é altamente superestimada." (Um dos autores é membro do National Dairy Council).

"Evidências substanciais indicam que o consumo diário maior que o das doses diárias recomendadas (DDR) de cálcio, ácido fólico, vitamina $E$, selênio e cromo reduzem o risco de certas doenças para algumas pessoas." (O autor da revisão é um cientista do Council for Responsible Nutrition, associação comercial da indústria de suplementos).

"Existem razões para preocupações que o baixo consumo de $\mathrm{NaCl}$ (sal) possa levar a riscos metabólicos de longo termo que ainda não foram completamente identificados... Nós não temos sólida evidência de que o baixo consumo de $\mathrm{NaCl}$ pode prevenir ou controlar pressão alta." (O revisor foi financiado parcialmente pelo The Salt Institute, uma organização comercial da indústria do sal).

"Um consumo moderado de vinho ( 2 a 5 copos por dia) foi associado com uma taxa de redução da mortalidade da ordem de 24 a 31\%." (Esse estudo foi financiado parcialmente pelo The French Technical Institute of Wine).

Fonte: Nestle (2002), tradução da autora.

Caderno eletrônico de Ciências Sociais, Vitória, v. 1, n. 1, p. 18-40. 
Nestle (2002) apresenta, ainda, os diferentes tipos de lobby das indústrias de alimentos que incluem diversas formas de parceria. A autora descreve as práticas de lobby no sistema político dos EUA como atividades legais, que excluem explicitamente a ação de suborno, e que são designadas para influenciar o Congresso, agências federais e o governo no sentido de fazer leis que beneficiem as companhias alimentares. Os lobistas oferecem conselhos técnicos apoiados pela pesquisa científica e propõem legislação, regulação e práticas de educação, sem ser, entretanto, legalmente eleitos pelo voto dos cidadãos. Outros métodos de lobistas incluem contatos pessoais estabelecidos em ocasiões sociais, contribuições para campanhas políticas, organização de eventos de mídia e de demonstrações públicas, bem como o apoio financeiro à pesquisa de profissionais da área da alimentação, especialmente daqueles ligados à academia, apoio a periódicos, suplementos científicos e grupos de aconselhamento sobre nutrição e saúde, congressos e conferências.

Nestle (2002) menciona importantes periódicos norte-americanos, como o Journal of Nutrition e o American Journal of Clinical Nutrition, bem como algumas das indústrias e associações que os apoiam financeiramente: Coca-Cola, Gerber, Nestlé, Monsanto, Roche Vitamins, The Sugar Association, Slim Fast Foods, entre outras. Entre os grupos e associações de renome que promovem a nutrição e a saúde, a autora cita, entre outras, a American Cancer Society, o American College of Nutrition, o American Council on Science and Health e a American Society for Clinical Nutrition, apoiadas por empresas diversas como Dairy Council, Novartis, Mead Johnson, Coca-Cola, Nestlé USA e Kraft Foods (Philip Morris). Para a nutricionista, nessa trama de relações fica difícil determinar onde a prática da ciência transforma-se em propaganda ou business.

Por outro lado, sabe-se que é muito oneroso produzir ciência sem financiamento. A edição de periódicos é cara; produzir estudos requer patrocínio; congressos e simpósios exigem verbas e parcerias para sua viabilização; e as universidades não conseguem manter laboratórios e materiais de pesquisa e extensão.

A própria ciência tem aberto espaço para estudos que analisam essa problemática ou sinalizam problemas que surgem a partir dessas parcerias. Exemplos citados por Nestle (2002) destacam que 30\% de membros de universidades aceitam financiamento de indústrias; $34 \%$ dos autores principais de 800 artigos científicos na área de biologia molecular e medicina estão envolvidos com patentes e consultorias de comitês ou estão envolvidos em companhias que podem se beneficiar com a pesquisa 
desenvolvida. A pesquisa britânica citada por Cannon (1987) verificou que de 246 membros de comitês nacionais em nutrição e políticas de alimentação 158 são consultores ou recebem financiamentos de empresas alimentares.

Sumarizando, a questão é se a origem do financiamento influencia o conteúdo das conferências e do currículo universitário, e o resultado das pesquisas e a publicação dos artigos científicos. Para a grande maioria dos cientistas e especialistas, essa pergunta é ofensiva e o respeito à ética é, em geral, evocado. O fato é que se o pesquisador não aceita apoio financeiro, não realiza pesquisa ou acaba solitário; por outro lado, se aceita apoio, suas visões pessoais serão necessariamente comprometidas pelo perfil do financiador? $O$ pesquisador pode ir contra os interesses de quem o apoia? Pode, ainda, trair suas convicções e seus valores éticos? Estes são dilemas de difícil abordagem.

As indagações acima podem, porém, ser avaliadas para além do âmbito da ética, em uma área muito mais objetiva: é na área da saúde pública que se percebem as repercussões sobre a saúde humana do estímulo a orientações nutricionais equivocadas, resultado frequente dessa arena de negociações.

Esses exemplos e problemáticas podem ser ampliados na perspectiva do embate entre os interesses comerciais das indústrias de alimentos frente às questões de saúde pública. Considerando, por exemplo, a questão de alimentos não tão saudáveis como os doces: não seriam pertinentes mais intervenções e recomendações baseadas em pesquisas, no sentido de prevenir a incidência de obesidade na população? O açúcar é um tipo de alimento cujo rótulo deveria alertar o consumidor sobre o perigo do seu consumo em excesso. Isso já ocorre com os alimentos funcionais, como a aveia, em cujos rótulos há indicação positiva sobre seu uso na prevenção de doenças cardíacas. Mas qual empresário da indústria de açúcar aceitaria tais condições? Quem pode regularizar essa situação? E se tais restrições chegassem a alimentos cujas restrições não são consenso entre os especialistas, como a carne, o leite ou a soja?

Outra questão diz respeito ao investimento massivo em pesquisas da área de biotecnologia agrícola. Altieri (2002) sinaliza que esse tipo de pesquisa precisa ser avaliado quanto a sua legitimidade frente aos sérios problemas ambientais que emergiram nos últimos anos. $O$ autor questiona se os fundos para desenvolvimento desses produtos e tecnologias não seriam mais bem aplicados no desenvolvimento de produção de alimentos com menor impacto ambiental. Um exemplo disso são as pesquisas voltadas para o desenvolvimento do arroz dourado, um produto geneticamente 
manipulado no qual foi inserido o gene do betacaroteno para aumentar o teor de vitamina $A$ do cereal. $O$ arroz dourado é um transgênico criado com a intenção de reduzir a deficiência de vitamina $A$ em populações que tradicionalmente alimentam-se com 0 arroz. Os custos da pesquisa (financeiros e ambientais, inclusive, como o risco da polinização cruzada contaminando espécies de arroz não transgênicas) valem a pena? Os brasileiros que sofrem de hipovitamionose $A$ - presentes em áreas endêmicas definidas por Pinheiro et al. (2004) como os bolsões de pobreza terão acesso a esse alimento? A educação nutricional incentivando o consumo e a diversificação de espécies vegetais nativas, ricas em vitamina A, cultivadas com baixo impacto ambiental não seria uma solução mais ajustada às reais necessidades do Brasil?

Muitos pesquisadores do sistema alimentar lidam com ciências agrícolas. Eles são vinculados aos departamentos e ministérios de agricultura e universidades públicas para encontrar maneiras mais eficientes e rentáveis de produzir bens primários. No entanto, a maior predominância das pesquisas em alimentação deve-se a pesquisadores empregados por empresas de alimentação ou de insumos e tecnologia agrícola para desenvolver novas técnicas. A maioria dos estudos é financiada por fundos públicos, através de instituições públicas ligadas ao governo. À medida que a indústria de alimentos se fortaleceu, ela começou, porém, a financiar sua própria pesquisa e uma das consequências disso é a baixa qualidade de estudos na área de alimentação, comparada com outras áreas de pesquisa. As empresas mantêm os resultados até comprovar seus benefícios para a indústria e isto é particularmente preocupante no caso das biotecnologias, para as quais existem tentativas de se utilizar de patentes para controlar 0 uso de algumas descobertas (TANSEY; WORSLEY, 1995).

Esse é um dos aspectos dos riscos da biotecnologia frente ao sistema alimentar. Nessa área, surgem novos riscos. Para Kennedy (1993), a biotecnologia na alimentação introduziu uma nova era. Ela pode abrir novos mercados, oferecer novos produtos, alterar padrões de negócios internacionais e o espectro da ciência, além de criar novos tipos de trabalhadores. Mas pode também extinguir muitos outros, de perfil tradicional, como os agricultores.

Goodman e Redcliff (1991) também destacam como um dos resultados da biotecnologia a mudança no perfil de vários atores do sistema alimentar, desde os agricultores até os consumidores. E acrescentam que a direção e a força dessas inovações direcionadas pelo sistema alimentar vão depender do equilíbrio das forças que controlam as agendas de política e de pesquisa. 
A habilidade para monitorar, usar e controlar informações e resultados de pesquisa é a chave para o sucesso de muitos atores no sistema agroalimentar atual. As informações de especialistas precisariam ser traduzidas para se transformar em conhecimento útil. De acordo com Tansey e Worsley (1995), consumidores e agricultores tendem a buscar informações públicas, enquanto outros atores mais influentes usam fontes de informação privadas. Algumas eles próprios produzem, outras eles compram na forma de resultados de pesquisa e tecnologia, pesquisas de marketing ou conselhos de especialistas.

A pesquisa em marketing na indústria alimentícia é muito desenvolvida e usa sofisticados modelos de teorias de comportamento humano derivados da Psicologia, Economia, Sociologia, entre outras disciplinas, bem como dinâmicas variadas, como grupo focais e outras técnicas qualitativas. 0 marketing e a propaganda de alimentos, como atores dessa arena de riscos alimentares, merecem ser analisados com profundidade em estudos posteriores.

Mais uma característica da análise construtivista frente aos riscos diz respeito às controvérsias, ou seja, à falta de consenso da ciência a respeito deles. Pode-se dizer que existem divergências e desacordos científicos frente às escalas de quase todas as avaliações de riscos, uma vez que os cientistas representam uma variedade de grupos de pressão e instituições interessados no tema.

Michel Callon (1986) ressalta que o estudo das controvérsias desenvolvido por diversos autores, como Collins e Pinch, Shapin e Mackenzie, contribuiu para o descrédito da visão de que a ciência e a tecnologia são livres de qualquer influência que não a intelectual. $E$ adiciona que as controvérsias são na verdade "impuras e heterogêneas" e "se as hesitações, mudanças e evoluções que marcam seu desenvolvimento devem ser compreendidas, então os interesses, estratégias e relações de poder que não param na porta do laboratório devem ser trazidos para o escopo da análise" (CALLON, 1986, p. 19). Compreender as controvérsias significa utilizar uma ferramenta metodológica para apreender as dimensões sociais e políticas da ciência. Nesse campo, é possível conhecer as dinâmicas da produção científica e tecnológica em suas relações com a sociedade (PINCH; LEUNBERGER, 2006).

A arena política das controvérsias cientificas na alimentação pode ser mais bem compreendida através de estudos como o de Azevedo (2011), que aborda as controvérsias que envolvem a soja, e o de David e Guivant (2012), que mostra a mudança de postura da indústria alimentar frente aos 
ácidos graxos trans a partir do surgimento das controvérsias que apontam o risco dessa gordura.

Outro tema complexo é a dificuldade de separar o social do científico nas avaliações técnicas. Para Irwin (2001), cálculos sofisticados de riscos dependem de julgamentos sociais e institucionais, tanto como de probabilidades de que os procedimentos de segurança serão seguidos ou de que os componentes foram corretamente fabricados. No caso da epidemia da doença da vaca louca que atingiu a Europa na década de 1990, por exemplo, as avaliações efetivas de riscos dependeram de julgamentos sociais e institucionais sobre a prática de manejo animal e as condições de abate.

Discutindo alguns exemplos de riscos ambientais, Wynne (1989) define certos julgamentos sociais como uma forma de sociologia ingênua. Guivant (2002) remete a esse conceito para se referir a uma sociologia assumida pelos peritos que realizam estudos sobre os riscos e concebem o mundo real de forma equivalente ao mundo dos laboratórios, impregnando de juízos equivocados as análises técnicas dos riscos.

Reportando-se ainda ao caso da doença da vaca louca, que se configurou como um legítimo risco ambiental, Irwin (2001) observa a dificuldade de fixar uma distinção entre o social e o natural. Lembrando que a vaca moderna é o produto de várias gerações de modificações genéticas e controle humano de crescimento e produtividade, o autor afirma que é muito difícil perceber onde o elemento social de produção animal industrial termina e onde a natureza intrínseca do animal começa. Nesse caso, ambos são parte de uma "rede humano-animal de interações" (IRWIN, 2001, p. 80). Um fenômeno natural passou a ser, portanto, uma categoria ambígua na modernidade reflexiva.

Irwin (2001) destaca uma relação social-natural ambígua e complexa, na qual nem o social nem o natural podem ser vistos como independentes ou autossuficientes. O autor ressalta, ainda, que diante da impossibilidade de manter uma fronteira fixa entre o social e o natural a identidade da disciplina Sociologia é diretamente afetada.

Para Irwin (1995), o que é natural está mais do que nunca confundido com o social e a natureza tornou-se um espaço de decisões práticas e éticas delineadas pela reflexividade humana. Porém, essa afirmação não dá garantia de controle humano sobre a natureza, que parece sempre reagir inesperadamente, sem que seja possível conhecer a amplitude e as repercussões dos riscos ambientais.

Nesse contexto de dificuldade em distinguir o social do natural e o social do científico cabe referendar Latour (1992, p. 2) e seu "processo de 
hibridização" ou o que ele chama de colapso de categorias. Esse autor defende que Economia, Ciência, Cultura, Natureza são híbridos que ultrapassam as barreiras convencionais ou negam a validade de tais limites e não podem ser estudados independentes uns do outros (apesar de que ainda ocorre frequentemente a divisão da ciência em categorias isoladas). Como consequência do processo de hibridização, os assuntos relacionados à ciência e à tecnologia tornam-se centrais para compreender a vida social contemporânea.

É possível pensar também na problemática da falta de informação ou, de forma mais elaborada, na dimensão cultural dos riscos. Douglas e Wildavsky (1982) enfatizam que a razão pela qual as pessoas realçam alguns riscos em detrimento de outros está enraizada no fator cultural. Para os autores, o risco é um fenômeno cultural relativo percebido de forma diferenciada dependendo dos interesses, ideologias e políticas que estão em jogo para determinar sua natureza e sua abrangência. Apesar do caráter democrático dos riscos ambientais, o risco eleito por um determinado sujeito ou grupo nem sempre é aquele que atinge a todos indistintamente.

No Brasil, a questão dos riscos ligados à alimentação - como no caso dos escândalos europeus da gripe aviária, da febre aftosa, da doença da vaca louca, do uso de carne de cavalo na indústria alimentar - deve ganhar outra dimensão.

O país ainda sofre com os problemas da desigualdade social e, consequentemente, com os riscos relacionados à falta de alimentos, o que pode explicar a minimização de muitos riscos alimentares. Percebem-se aqui as consequências de uma sociedade de risco, sem a reflexividade ativa que caracteriza alguns setores dos países desenvolvidos no que concerne ao controle da qualidade dos alimentos. Sem desconsiderar a complexidade da arena de eleição e legitimação dos riscos e a perspectiva de que as escolhas alimentares não são feitas num âmbito de total liberdade de escolha, as falhas na comunicação dos riscos podem também estar associadas à ignorância ou à falta de informação. Por outro lado, existem as consequências de muita informação e muito alarde em torno de grandes problemas que podem gerar apatia e indiferença (GUIVANT, 2000).

Irwin $(1995$, p. 77) destaca o caráter eminentemente social dos riscos: "[...] os juízos acerca de risco e segurança vão refletir a posição pessoal na estrutura social - e também o grau pessoal de confiança nas instituições sociais que realmente decidem sobre estas questões". Se a ciência já teve mais legitimidade junto às instituições sociais, atualmente seu papel é questionado. Esse aspecto se mescla com a questão da credibilidade e confiança do público. Problemas de legitimidade institucional não significam 
que as mensagens oficiais são totalmente desacreditadas ou rejeitadas, mas abrem uma discussão que envolve um público crítico e reflexivo, e também a possibilidade de que afirmações governamentais sejam recebidas com ceticismo. No caso das sementes transgênicas, os interesses próximos entre as empresas produtoras de sementes e o governo estimularam reações de desconfiança em produtores e consumidores. Grande parte dos riscos ambientais é inevitavelmente conectada com assuntos que dizem respeito à credibilidade pública frente a instituições governamentais.

Irwin (2001, p. 85) sugere a necessidade de "flexibilidade e mentes abertas frente aos riscos e problemas ambientais". Considerar separadamente as reivindicações de governantes, ambientalistas ou cientistas como determinantes é perder um dos "mais fascinantes elementos do debate sobre riscos ambientais: a maneira através das quais os híbridos ambientais são construídos, contestados e defendidos em arenas sociais, científicas e institucionais" (IRWIN, 2001, p. 86).

Esse mesmo autor identifica não somente uma variedade de contextos institucionais e disciplinas científicas, mas também outro aspecto que diz respeito à divisão científica do trabalho. No risco de contaminação dos alimentos por agrotóxicos, a ciência inclui a submissão de dossiês para aprovação e a atuação de comitês científicos que decidem que testes devem ser feitos e que tipos de evidências são requeridos antes de se liberar determinado agroquímico. Dessa forma, a especialidade científica influencia a forma de controle público e regulador relacionado a perigos específicos.

Para finalizar essa abordagem, Irwin (2001) ressalta o caráter altamente diferenciado da ciência na área de riscos ambientais e alimentares, o que pode confundir o que habitualmente se pensa como atividade científica. Essa diferenciação sugere uma complexidade social para as atividades científicas, mas também uma sobreposição com preocupações sociais, institucionais e ambientais. O estudo de Azevedo e Rigon (2010), que destaca as repercussões econômicas, sociais, culturais, ambientais e sobre a saúde humana do sistema agroalimentar moderno, influenciando no conceito de alimento saudável, pode ilustrar a afirmação de Irwin.

Todos os aspectos acima são inseparáveis e quanto maior a aproximação das questões específicas do desenvolvimento científico mais as grandes categorias de sociedade, natureza e conhecimento se mesclam.

Juntando todos esses pontos de vista, percebe-se que a relação entre a ciência e a avaliação dos riscos alimentares é mais complexa e multifacetada do que parece à primeira vista. Tal análise de riscos, sob a perspectiva da ciência, conduz, assim, a novas premissas. 
A interpretação e a construção dos riscos alimentares são contestáveis e frequentemente partidárias, uma vez que os vários grupos envolvidos usam a linguagem da ciência para defender seus interesses. Nessa perspectiva, mais pesquisas nem sempre podem resolver as controvérsias que surgem - na verdade, mais ciência pode, algumas vezes, exacerbar os desacordos existentes.

Latour (2001, p. 47), ao proclamar que "uma ciência sempre oculta outra", sugere a necessidade de pesquisas de caráter inter e transdisciplinares. Tais pesquisas podem ajudar a minimizar a visão reducionista que impera nos estudos de riscos alimentares. Beck (1992) também desafia a ciência a encontrar outras formas de operar na sociedade de risco a partir de uma nova relação entre racionalidade científica e racionalidade social.

Irwin (2001) defende não somente uma perspectiva analítica, mas também uma metodologia particular ao insistir sobre a necessidade de examinar a contextualização dos processos de riscos ambientais, adotando uma abordagem situacional para essas preocupações. Essa abordagem no campo da alimentação deve considerar as diferentes construções ambientais e os diferentes grupos de atores sociais envolvidos na formulação e defesa dos riscos, estimulando a participação do consumidor e diluindo a figura de lideranças e autoridades formais, analisando cada caso de forma particular. Guivant (2002) enfatiza ainda a necessidade de se considerar as diferentes relações que se estabelecem entre leigos e peritos e as especificidades entre os países dos hemisférios Norte e Sul. Tal metodologia insere o ato biológico de comer em um contexto de politização da alimentação abordado por Portilho, Castaneda e Castro (2011).

Para colocar em prática essa metodologia, destacam-se três desafios: não limitar a análise sociológica ao estudo dos desafios e impactos sociais; considerar a heterogeneidade e a variedade científica; e enfatizar o contexto e as situações particulares dentro dos quais os fatos são construídos e defendidos. Essa é uma metodologia que implica em rastrear os atores e observar cuidadosamente como todas as evidências são acumuladas e organizadas pelos diferentes grupos de indivíduos e instituições (IRWIN, 2001). Para esse autor, tal perspectiva pode gerar uma série de questões desagradáveis sobre a ciência e sua aplicabilidade nas discussões e debates de riscos ambientais. Na verdade, a ciência torna-se uma arena legítima para o debate público e não somente um referendo incontentável nas resoluções de disputas ambientais. 


\section{Considerações finais}

Fica claro que a nova ciência que deve emergir não dispõe de um método irrefutável e muito menos dispensável, mas de um conjunto de instituições sociais difusas e flexíveis, em constante negociação e com uma característica política que não pode ser mais ignorada.

De qualquer forma, a ciência ainda é percebida como um dos meios mais seguros de interpretar e definir os riscos alimentares. Com suporte financeiro e técnico, a ciência continua ampliando sua compressão sobre o tema e é uma base sólida para ações sociais e institucionais que utilizam os parâmetros por ela definidos. Entretanto, ela vem perdendo sua homogeneidade e já se pensa não em uma ciência, mas em diversas ciências que incluam as preocupações mais amplas dos cidadãos, além de outros atores, na sua rede. Assim sendo, a ciência democratiza-se e pode tornar-se palco de ações de cidadania.

Essa discussão que envolve diferentes atores merece ser aprofundada no Brasil através de estudos sociológicos empíricos que se debrucem sobre a desqualificada arena social e cultural de riscos alimentares, pesquisando a percepção e o comportamento dos consumidores e especialistas, o papel das agências reguladoras e dos institutos de defesa dos consumidores, o impacto dos riscos e controvérsias alimentares, entre outros temas que permitam compreender como se estabelece o processo de democratização da ciência no Brasil e como a sociedade compreende os riscos alimentares e responde diante dos mesmos. Tais estudos podem embasar ações de controle de riscos alimentares, bem como aperfeiçoar mercados consumidores e estimular sistemas agroalimentares preocupados com a segurança alimentar e nutricional.

\section{Referências}

ALTIERI, M. 2002. Biotecnologia agrícola: mitos, riscos ambientais e alternativas. Porto Alegre: EMATER-RS.

AZEVEDO, E. 2011. Riscos e controvérsias na construção social do conceito de alimento saudável: o caso da soja. Revista de Saúde Pública. v.45, p.781-788.

AZEVEDO, E.; RIGON, S. A. 2010. Sistema Alimentar com base no conceito de Sustentabilidade. In: TADDEI, J. A.; LANG, R. M. F.; LONGO-SILVA, G.; TOLONI, M.H.A. (orgs.). Nutrição em Saúde Pública. São Paulo: Editora Rubio, p. 543-60.

BAUMAN, Z. 2001. Modernidade líquida. Rio de Janeiro: Jorge Zahar. 
BEARDSWORTH, A.; KEIL, T. 1997. Sociology on the menu. London: Routdedge.

BECK, U. 1995. Ecological Enlightenment: essays on the politics of the risk society. New Jersey: Humanities Press, 1995.

. 1992. Risk Society: towards a new modernity. London: Sages.

BURCH, D.; LAWRENCE, G. 2010. The "Wellness" Phenomenon: Implications for Global Agri-food Systems. In: LAWRENCE, G.; LYONS, K.; WALLINGTON, T. (org.). Food Security Nutrition and Sustainability. London: Earthscan.

CALLON M. 1986. The Sociology of an Actor-Network: The Case of the Electric Vehicle. In: CALLON, M.; LAW, J.; RIP, A. (ed.), Mapping the Dynamics of Science and Technology. London: The Macmillan, p. 19-34. CANNON, G. 1987. The Politics of Food. London: Century Hutchinson, 1987.

DAVID, M.; GUIVANT, J. S. 2012. A gordura trans: entre as controvérsias científicas e as estratégias da indústria alimentar. Política \& Sociedade Volume. v. 11 , n. 20, p. 49-74.

DOUGLAS, M.; WILDAVSKY, A. 1982. Risk and Culture: an essay on the selection of technological and environmental dangers. Berkeley, Los Angeles e London: University of California Press.

FALLON, S.; ENIG, M. G. 2000. Tragedy and Hope-The Third International Soy Symposium. Townsend Letter for Doctors and Patients, 66-70. Disponível em: [http://www.tldp.com/issue/11_00/soy.html]. Acesso em: [5 abr. 2007].

GIDDENS, A. 2002. Modernidade e Identidade. Rio de Janeiro: Jorge Zahar Editor.

GIDDENS, A.; BECK, U.; LASCH, S. 1995. Modernização reflexiva. Política, tradição e estética na ordem social moderna. São Paulo: Editora da Unesp.

GOODMAN, D.; REDCLIFT, M. 1991. Refashioning Nature. Food, ecology and culture. London: Routledge.

GUIVANT, J. S. 2005. A governança dos riscos e os desafios para a redefinicão de riscos no Brasil. In: SANTOS, M. M.; VOGT, C.; FRANÇA, J. G. E.; GUIVANT, J. S. (orgs); Ciência, Tecnologia e Sociedade. Novos Modelos de Governança. Brasília: CGEE, p.47-85.

2002. Riscos Alimentares: Novos Desafios Para a Sociologia Ambiental e a Teoria Social. Revista Desenvolvimento e Meio Ambiente; v.5, p. 89- 99.

. 2000. Reflexividade na sociedade de risco: conflitos entre leigos e peritos sobre os agrotóxicos. In: SELENE, Herculano (org.), Qualidade de vida e riscos ambientais. Niterói: Editora da UFF, p. 281-303. 
HANNIGAN, J. A. 2006. Envinromental Sociology: a social connstructionist perspective. A formação de uma perspectiva social. London: Routlegde.

HINCHLIFFE, S. 2001. Indeterminacy in-decisions - science, policy and politics in the BSE (Bovine Spongiform Encephalopathy) crisis. Great Britain: Trans Inst Br Geogr.

IRWIN, A. 2001. Sociology and the Environment. A critical introduction to society, nature and knowledge. London: Polity Press. . 1995. Ciência Cidadã. Lisboa: Instituto Piaget.

IRWIN, A; MCCARTHY, E; ROTHSTEIN, H; YEARLEY,S. 1997. Regulatory Science and the European control of agrochemicals. In: BAL; R; HAFFMAN, W (eds). The Politics of Chemical Risk: scenarios for a regulatory future. Dordrecht, Boston, London: Kluver, p. 231-59.

JARVIE, I.; AGASSI,J. 2011. Por uma sociologia crítica da ciência. Sociologias; v. 13, n. 26, p. 43-83.

JASANOFF, F. 1986. Risk Management and Political Culture: a comparative study of science in the policy context. New York: Russel Sage Foundation.

KENNEDY, P. 1993. Preparing for the twenty-first century. New York: Random House.

LATOUR, B. 2001. A esperança de Pandora. Ensaios sobre a realidade dos estudos científicos. Bauru: EDUSC.

1992. We have never been modern. London: Harvester Wheatsheaf.

NESTLE, M. 2002. Food Politics. Berkley, Los Angeles, London. University of California Press.

PESSANHA, L.; WILKINSON, J. 2005. Transgênicos, Recursos Genéticos e Segurança Alimentar. O que está em jogo nos debates? Campinas: Armazém do Ipê (autores associados).

PINCH, Y.; LEUNBERGER, C. 2006. Studying scientific controversy from the STS perspective. Department of Science \& Technology Studies, Cornell University. Disponível em: [http://ionesco.sciencespo.fr/com/moodledata/3/Pinch_Leuenberger_Controversies.pdf]. Acesso em: [5 nov. 2009].

PINHEIRO, A. R. O.; FRITZEN, C.; AQUINO, K.; VIANA, R. G. 2004. Diagnostico de Saúde e Nutrição da População do Campo: Levantamento de Dados. Ministério da Saúde. Secretaria de Atenção à Saúde. Departamento de atenção básica. Coordenação-Geral da Política de Alimentação e Nutrição. Disponível em: [http://189.28.128.100/nutricao/docs/geral/diagnosticoSaude.pdf]. Acesso em: [14 Mar. 2013]. 
PORTILHO, F.; CASTANEDA, M.; CASTRO, I. R. R. 2011. A alimentação no contexto contemporâneo: consumo, ação política e sustentabilidade. Ciênc. saúde coletiva v. 16, n. 1, Jan.

TANSEY, G.; WORSLEY, T. 1995. The Food System. A Guide. London: Earthscan Publication.

SALTER, L. 1988. Mandated science: science and scientists in the making of standards. Boston: Kluwer Academic Publishers, 1988.

WYNNE, B. 1992. Uncertainty and Environmental Learning. Global Environmental; v. 2, n.2, p. 111-127.

1989. Frameworks of rationality in risk management: towards the testing of naive sociology. In: BROWN, J. (ed.). Environmental threats: perception, analysis and management. London: Belhaven Press. 